\title{
Principles of Describing a Private Rhetoric Genres System
}

\author{
Tatiana Anisimova ${ }^{1}$, Svetlana Chubay $^{1 *}$, and Natalia Prigarina $^{2}$ \\ ${ }^{1}$ Volgograd State University, 400062, Universitetskiy av., 100, Volgograd, Russia \\ ${ }^{2}$ Volgograd State Socio-Pedagogical University, 400066 Volgograd, Lenin Av. 27, Russia
}

\begin{abstract}
The article states that the basis of the specialist's speech competence constitutes the ability to create appealing speech works in the required genre in accordance with the situation, the audience and the communication goals. In this regard, it is evident that the development of private rhetoric is necessary for various professional spheres. The authors describe the principles of building such rhetoric as a system of professionally significant genres and propose a specific variant of the genre model, focused on a rhetorical understanding of professional communication. This model includes not only the positions which are traditionally included in the model of the speech genre (addressee and addresser, the purpose of speech and etc.) but also the positions which are characteristic only of a rhetorical genre (the value system and composition), and, what is more, these parameters are to form a recognizable "face" of a rhetorical genre.
\end{abstract}

Key words: speech competence of a specialist, private rhetoric, rhetorical genre, genre model.

\section{Introduction}

The issue of studying the oral speech genres is increasingly attracting the attention of scientists. So far, a science of genre studies has already formed and is focused on the search of criteria to describe different genres that function in separate spheres of communication. It "involves studying the language along with the speaker oneself taking into account the intuition and introspection" [1]. This fact ensures us that in the near future the stated sphere will become a full-fledged scientific theory with its own categorical apparatus, understandable and suitable for describing any speech genre. However, at this stage, the genres are studied very erratically.

As it is known, Mikhail Bakhtin subdivided all genres into primary and secondary ones [2]. In relation to oral speech, we should consider the primary genres to include those which are developed in the terms of direct communication. They are not specially prepared in advance, as a rule, and have a simple composition and a simple unsegmented thesis (cf.: advice, request, comment, etc.). Secondary are the genres which are certainly thought out and prepared in advance (cf.: report, proclamation, inaugural address, etc.). They usually have a complex composition and a complex multipartite thesis. Secondary genres can base on primary ones (cf:: greeting - anniversary speech) or include them in its structure (in addition to the above, the primary genres lose their independence and can no longer be described as genres). V.V. Dementiev names this phenomenon as diachronic speech and genre replication, involving relations of a sequence in time [3]. There may be occasions when a simple question on the vital issue is thought over by an individual for a long time, and the speech is given unprepared at the meeting. However, in this case, the issue must also produce the impression of spontaneous speech, and the speech at the meeting must sound as a complete meaningful text and include decent parts. In modern practice, the primary genres are considered speech genres (a person masters them intuitively when communicating with other people), and the secondary ones - rhetorical (people need to master them and build them according to the rules).

The study of publications on the genre theory shows that the vast majority of scientists focus on the study of primary speech genres (both monologic: compliment [4], acknowledgement [5], request [6], apology [7], etc., and dialogical: intimate talk [8], table talk [9], etc.). However, rhetorical genres bound to typical situations of professional communication are particularly important for teaching professional speech to future specialists. The system of such genres, which are necessary to experts of a certain profile, forms a separate private rhetoric (legal, educational, administrative, and political, etc.). In contrast to general rhetoric, which describes the procedure of creating any speech and relies on ancient rhetorical canon (i.e. common rhetoric is based on the logic of rhetoric), private rhetoric must view professionally relevant situations from a rhetorical point of view (i.e. private rhetoric is based on the logic of the corresponding activity). Thus, the main purpose of private rhetoric is to describe the system of genres relevant to a specific professional field, which is focused on active speech communication where speech is a tool for managing activity. Therefore, we may allocate as many separate private rhetorics as many professional spheres can be found. Moreover, the greater importance the speech has for the success of the professional activity, the more developed and demanded a

\footnotetext{
*Corresponding author: sa_chubai@ volsu.ru
} 
corresponding private rhetoric becomes. So, science has always shown interest to the genres of pedagogical communication, and their specificity is covered in many studies. The interest in legal rhetoric was especially large in those days when judicial practice attracted the jury, and the impact on the audience through language was important. In connection with Russia's transition to a multi-party system and free election system to the 90 -s of the twentieth century, political rhetoric was rapidly developing.

\section{The concept of a private rhetoric genres system}

All genres, included in the composition of a particular private rhetoric, should form a coherent system.

The concept of a "system" in this case includes two aspects:

1) Genres should be described according to the same model in order to make the specificity of each genre clearly visible compared to others. This is a very significant problem because when characterizing one genre, authors of modern textbooks often indicate its task, the other - its composition, the third - its linguistic peculiarities and the reader gets no criterion for distinguishing between the genres. It should be noted that the rhetorical approach to the description of the genre involves a purely technological approach, but not a descriptive, narrative, more accepted in linguistics, i.e. a procedure of creating speech is necessarily presented in the studied genre. A rhetorical approach consists in describing how to build an utterance so that the speaker's task in this particular situation can be performed as well. It is extremely important for education because using genres intuitively people, who do not always act properly, take into account genre specifics, and follow a particular rhetoric form. Then the treatment becomes similar to advertising and welcome speech - to the annual report.

2) When describing genres, we should show their place in the system of the expert's activity. For example, when a managerial rhetoric is created, it is necessary to bind its content to the course on management. This is particularly important because the very essence of the management activities concerns the need for the constant coordination of work in the divisions of the organization to achieve common goals. Such coordination is carried out in various forms but first and foremost through diverse contacts between members of the organization, i.e. within the communication process. The fact that all other managerial functions are implemented through the communicative function makes the data clear showing that from $60 \%$ to $90 \%$ of the total working time of the head is occupied with communication. In this regard, the managerial rhetoric uses the logic of management theory in order to clarify which genres a manager needs to master to successfully implement a particular control function. So, to implement the planning function one needs to master the genres of opinion, proposal, objection, etc.; the function of the organization - of request, demand, claim, etc.; the function of motivation
- panegyric, compliment, felicitation, etc.; the monitoring function - report, reprimanding, reflection, etc.; and it is indicated everywhere at what stage and for what purpose every genre is used. Thus, the task of rhetoric for managers (and of any other professionallyoriented rhetoric) includes the need to analyze the content of professional manager's activity from the rhetorical point of view and complement all sections of appropriate textbooks about forms of communication with the rhetorical information. The rhetorical data should be theoretically included as separate paragraphs in the textbooks on management. So, the section "personnel management" must be complemented with a detailed description of the peculiarity of genres required when dealing with staff, and section "meetings organization" - a description of the structure and content of the genres used in the process of meeting and negotiating, etc.

\section{Model of a rhetorical genre}

To build the above-described system, it is first necessary to have a clear model of the genre based on the actual rhetorical principles. The main parameters of the genre description in different ways are used by many authors attempting to create such model. The rhetorical genre model is based on the ancient rhetorical canon (the set of rules and laws on nurturing, building and uttering the speech) which passes through the stages of invention, disposition, elocution, memorizing, and uttering [10]. "Rhetorical texts differ from nontechnical with their essential feature: language texts are produced by native speakers spontaneously, explicit rules are relevant here only for the researcher who builds a logical model of unconscious processes. Within rhetoric, the process of generating texts has a 'scientist', conscious nature. The rules are actively included in the very text not only at the metalevel, but also at the level of direct textual structure" [11]. Thus, a rhetorical work is created deliberately and specifically to influence this audience in such a situation. To ensure that the impact took place, the speech must be relevant, which is manifested in the system of argumentation, construction (composition), wording and pronouncing. In accordance with this, we define a rhetorical genre as a sustainable type of rhetorical works, the unity of special properties of form and content, defined by the purpose and conditions of communication and focused on the anticipated reaction of the recipient.

The work on the speech starts with the analysis of the communication situation because the genres "correspond to typical situations" in the particular sphere of communication [2]. A situation is a set of conditions and circumstances that create the relations between its members, which require certain speech acts culminating in the creation of a specific genre. "Immediate and broader social environments wholly determine the structure of the utterance from the inside. $<\ldots>$ The situation shapes the utterance making it sound in the one way and not otherwise, like a requirement or request, like an assertion of the own rights or a prayer in an ornate or simple, confident or timid way, etc." [12]. It is 
obvious that different situations call for different speech acts and forms of expressing thoughts, i.e. genres. The same is the same. "Missing" the genre makes it difficult to communicate and may cause some conflicts. Thus, the situation refers not only to the specific situation (place, time, etc.) which is never repeated but also to a cause as a typical phenomenon of life. This is how we understand the situation when talking about its frequency, stability, and influence on the choice of genre.

The image of the speaker consciously generating speech is one of the most important parameters of the genre. The question of the speaker's social responsibility has long excited the minds of rhetoricians encouraging them to clarify the role of ethics in oratorical practice. This aspect demanded the description of the moral side of eloquence or personal paradigm of the speaker which could give the definition of the main components of oratorical activity. It includes ethos, logos and pathos of the speaker.

Characteristics of the recipient. The ability to adequately determine the characteristics of the audience enables the speaker to more accurately select the desired genre in similar situations and, accordingly, its content, composition, and language means of expression. For example, if the speaker is going to share the scientific information with the experts in the given scientific field, he or she does it in the form of a scientific report, and if he or she addresses a layperson, the form of popular science lectures is used. Speaking of the ways to accomplish some work, the speaker turns to the subordinate with an order, to the fellow with a recommendation and to the chief asking for permission. In any case, it is difficult to consider all the characteristics of the audience, but those that are important to achieve a certain impact must necessarily be taken into account.

One of the important genre characteristics of rhetorical works is the purpose. The purpose of the speech is the idea of the general result that should be achieved when performing the speech. The teleological nature of a rhetorical approach to generating the discourse requires a mandatory indication of the conscious or intuitive purpose of speech as a basic condition of achieving the planned result of the impact. According to the purpose, speech is divided into the informative that help students to generate new knowledge; epideictic that create a positive emotional state; persuasive that make us accept a new point of view on the subject; appealing to act in the proposed manner. It follows that we can talk about informative (message, report), epideictic (greeting, instruction), persuasive genres (accusatory speech, protest), and genres appealing for action (request, order). Within each type of speech, genres are brought together through a common goal typical of the whole group: to inform, to encourage, etc., but at the same time expressed in a specific way peculiar only to this genre. Further, the goal can be formulated in relation to the groups of genres which are close in meaning: a message consisting of some processed (secondary) information obtained from other sources (overview, summary, analysis), disagreement with the opponent (objection, contradiction, protest), etc. And finally, every genre has its specific task which can help to distinguish between close genres. So, the task of objection indicates disagreement with some words or actions of the opponent and points at weaknesses of his position; the task of contradiction provides a proof of conceptual infidelity (improbability) of opponent's thesis; the task of criticism is to discover and remedy insufficiency during socially significant activities, etc.

Then, at the invention stage, the content is created: the thesis of speech is formulated and the argumentative material is taken. Content is the actual text forming and "visible" element of speech. Each genre tends to the "own" typical content, i.e. the common, compulsory, and repetitive content in all speeches of this genre (e.g., the chronological sequence of steps in the instruction, panegyric in the greeting, grounding in the method of solving the problem in the proposal, etc.). The requirement to consider the basic idea of not only an individual speech but also large groups of statements goes back to Aristotle's judgment that the content of the epideictic speech includes something wonderful and shameful, deliberative speech - beneficial or harmful, judging speech - fair and unfair [10]. So, the typical content of the report includes the analysis of the work carried out for a certain period or any task performed; summary supposes the final speech with generalization of the data provided within the previous presentations.

Next, you need to specify the parameter of the genre which is usually not included in the genre model. However, it is perhaps the most important parameter characterizing both a separate genre and the system of genres of the private rhetoric from the most essential side: the system of special values that guide the speaker in his speech activities. Moreover, such standard values can be found in the private rhetoric on the whole and in its separate genres. They form a hierarchy, the description of which can lead to clarification of the general purpose of private rhetoric and the specifics of each genre.

For this reason, V.V. Dementiev expresses a very important idea: "Genre consistency reinforces the value system of the given society: on the one hand, each genre applies one or another social value that defines its purpose and significance; on the other hand, the genres, of course, have a considerable value for communication, and therefore for the society functioning" [13]. The fact that every genre (or a group of closely related genres) has its own value system should be used as the basis of the rhetorical classification. From this point of view, we can distinguish between several levels of values constituting the same hierarchy, which determines the specifics of a particular genre.

First of all, the values of institutional communication lead to the values of the respective institute, for example, political rhetoric will mostly demand freedom, democracy, equality, security of citizens, etc. Pedagogical rhetoric especially needs intellectual starvation, truth, and justice, etc. In the rhetoric of social interaction, the value of human communication comes to the foreground: "It seems warranted to consider the value of human communication as a universal one 
despite the existence of significant differences between certain forms of the standard communication process" in different circumstances [13]. The main value of managerial discourse concludes in promoting the development of the organization, quality of activities, and achievement of production purposes. As for the judiciary, the most relevant values should be those that are protected by law. In this regard, all crimes become the assassination attempt on those values. So, the values turn out to include life (respectively, the crime means murder), health (bodily injury), the inviolability of home and property (theft, robbery, etc.), honour and dignity (slander), etc. [14].

Next, we can allocate the values that correspond to the main activities in the area under consideration. So, management activity primarily implies management functions. For example, implementation of organizational functions will demand such values as optimization of relations between the employees, subordination; implementation of the motivation function will need enhancing competency, increasing creative potential; implementation of monitoring functions imply collectivism, conscientious attitude to work, etc.

Finally, we can highlight the values that define the specific nature of the certain genre. For example, felicitation would mainly include strengthening relationships (phatic function) and dignity of the birthday celebrant. Counselling includes the activities of the recipient which he should implement, and the results he should achieve. In reprimanding the main value is elimination of deficiencies in work, optimization of the joint work, for which the speaker could even sacrifice some part of (but not all) good relations. However, the relationship also bears some value (subordinate) as it needs improving. For presentation, the main value is represented by a new item, a good public attitude to it.

With the help of values, the function of forming moral ideals and social imperatives is realized. A crucial feature of the rhetorical impact is also manifested in implicit persuasion without didacticism and prescription. Thus, for example, inclusion in the judicial speech of such values as justice, inevitability of punishment for the committed crime, can perform an educational function and shape the worldview of students by indirect methods which are much more effective than direct moralizing. Similarly, it is more effective to encourage employees to work better with praising and appealing to collectivism, forming the pride for the institution and its success than using reprimands and exhortations. Building a hierarchy of values helps to choose the right tactics of manipulation: if the values that unite the speaker and the audience belong to a higher level, and those that oppose them belong to the lower, this opposition creates the basis for developing a common ground.

Rhetorical genres usually have a fairly rigid compositional scheme. It is the presence of certain semantic components (micro topics) that usually enable recognizing a specific rhetorical genre. If you omit even one obligatory micro topic, the speech soon begins to relate to another genre or becomes formless. This feature of genres is pointed out by many authors: "There is an illocutionary standard of the genre corresponding to a certain genre and stylistic prototype. 〈...> The inclusion of a request into the character reference turns this document into a solicitation, and a detailed narration of the facts from the life of a characterized person leads to the genre shift and turns the reference into a biography" [15], [16]. For example, felicitation necessarily includes the following micro topics: a congratulatory formula, a description of the virtues of honoree and wishes; a proposal, an indication of a common problem, the mechanism for its resolution, benefits and advantages of implementing the proposed; a panegyric, a description of the situation, an indication of what and why we praise the addressee, and also the emotional conclusion; an objection must contain the point of disagreement and its emotional assessment, displacing the antithesis, justifying the own thesis, etc. However, some genres allow (and even suggest) the possibility of attracting the optional micro topics at the request of the author. So, the speech in the debate can include the micro topic that contains a personal opinion of the speaker, but its absence does not violate the purity of the genre, felicitation may include or exclude the expression of gratitude to relatives, friends, superiors, and honorees that does not lead to destruction of the genre.

At the next stage, there are selected the language tools specific to the genre. One can talk about lofty, solemn language of proclamation or terminological and professional vocabulary of an academic lecture or a scientific paper. In a counselling speech, there appear vivid descriptions, so that the listener could not help understanding the speaker; and in greetings, a positive mood of the recipient is accompanied by the words of a positive assessment, vocabulary expressing the speaker's feelings to the honoree, various tropes and figures.

The stage of utterance includes direct communication of the speaker with the audience, implementation and accomplishment of creating a speech, because here the thoughts and words are supplied with the intonation, rhetorical gestures, and the whole look of the speaker expressing his emotional state, moral position and personal attitude to the content of the speech and to the audience. This stage is important from the standpoint of the genre theory as some genres face special requirements to speech utterances. So, reading congratulations "from a piece of paper" is puzzling, but there is no objection to reading the report. It is impossible to hope for the impact, if a persuasive speech is uttered sadly, without faith in what is being uttered. In some cases, failure to comply with the requirements of special uttering a speech leads to the complete destruction of the genre. So, the claim is necessarily a strong speech, and the instruction must include imperative modality.

The proposed model representing the totality of necessary genre forming features allows us to describe any rhetorical genre and to learn the procedure of creating an appealing speech in different situations. As a result of this work, a certain layout of speech arises to help the speaker to get into the situation, to match the chosen genre. For example, the genre of the report 
assumes that this is an informative speech with which a person, who has some official status (a scientist, a person instructed to speak on behalf of the team, the head of a collegiate authority), speaks for himself or on behalf of his team to a competent audience (a scientist assembly, an election meeting, a congress) in order to inform about latest results of the scientific work or the results of the activity of a body or a team. It is usually represented by a relatively bulky speech, complex in structure and rich in precise information. In addition to the final result, it usually includes a description of the way (procedure) which facilitated to achieve this result. And in contrast, for example, to lectures, where the retold data are already known to specialists, but not known to the given audience, the report tells fundamentally new, yet unknown information.

\section{Conclusion}

Today the demand for appealing spontaneous speech is increasing in terms of a certain deficiency in time. But in such terms, it is possible to do well only what one can. The ability to use the model of the genre needed in this situation can be considered as a requirement for the communicative competence of the speaker. "The better we possess the genres, the more freely we use them, the better and brighter we reveal our individuality in them" [2], [17]. And the more models of speech genres the modern humans have, the greater the number of situations he will feel comfortable and confident in. Particularly important ability is that to create rhetorical works of professionally important genres in accordance with the situation, the audience and the goals of communication when performing professional activities in any field.

\section{References}

1. V.M. Alpatov, Questions of linguistics (Topics in the study of language) 3, 7-21 (2015)

2. M.M. Bakhtin, Literary and critical articles, $428-472$ (M, 1986).

3. V.V. Dementiev, Topics in the study of language $\mathbf{6}$, 78-107 (2015).

4. K.F. Sedov, Speech Genres: collection of scientific articles 7 Genre and linguistic identity, 225-235 (Saratov: Publishing House "Nauka", 2011)

5. V.I. Karasik, Genres of speech: collection of scientific articles 7 Genre and linguistic identity, 225-235 (Saratov: Publishing House "Nauka", 2011)

6. G.M. Yarmarkin, Genres of speech: collection of scientific articles 3, 262-268 (Saratov: College, 2002)

7. I.S. Shevchenko, Genres of speech: collection of scientific articles 6, 329-337 (Saratov: Publishing House "Nauka", 2011)

8. I.V. Sherstyanykh, Kazan science 4, 79-82 (2017)
9. I.V. Kostina, Yaroslavl Pedagogical Bulletin 3(40), 24-30 (2004)

10. Aristotle, Rhetoric, Ancient rhetorics, 352 (M: Publishing House MSU, 1978)

11. Y.M. Lotman, Rhetoric 2, 92-108 (1995)

12. V.N. Voloshinov, Marxism and the philosophy of language: The main problems of sociological method in the science of language, 188 (M., 1993).

13. V.V. Dementiev, V.V. Fenina, Genres of speech: collection of scientific articles 4, 5-34 (Saratov: College, 2005)

14. A.P. Anisimov, T.V. Anisimova, A.Ya. Ryzhenkov, The Social Sciences 11 (6), 998-1007 (2016)

15. V.I. Karasik, Language of the social status, 495 (M., 1992)

16. E. Malushko, O. Maletina, V. Tsybaneva, Proceedings of the 7th International Scientific and Practical Conference Current Issues of Linguistics and Didactics: The Interdisciplinary Approach in Humanities (CILDIAH 2017) ASSEHR 97, 175180 (2017)

17. N.L. Shamne, E.V. Shishkina, Bulletin of Volgograd State University. Linguistics 16 (2), 143-151 (2017)

18. E.V. Bobyreva, O.A. Dmitrieva, M.R. Zheltukhina, M.V. Busygina, Proceedings of the 7th International Scientific and Practical Conference Current Issues of Linguistics and Didactics: The Interdisciplinary Approach in Humanities (CILDIAH 2017) ASSEHR 97, 52-56. (2017) 